\title{
The determination of highly time-resolved and source-separated black carbon emission rates using radon as a tracer of atmospheric dynamics
}

Asta Gregorič et al.

Correspondence to: Asta Gregorič (asta.gregoric@aerosol.eu)

The copyright of individual parts of the supplement might differ from the CC BY 4.0 License. 


\section{S1 Source apportionment of $B C$ : Estimation of the site specific $A A E_{T R}$ and $A A E_{B B}$ :}

The Aethalometer model (Sandradewi et al., 2008) uses an a priori assumed pair of absorption Ångström exponents $(A A E)$ for traffic $\left(A A E_{T R}\right)$ and biomass burning $\left(A A E_{B B}\right)$ to determine the contribution of both sources. $A$ narrow range of $A A E_{T R}(0.8-1.1)$ values is reported in the literature, whereas larger $A A E_{B B}$ values (from about 1.5 up to 3.5) in the wider range are characteristic for biomass burning sources (Kirchstetter, 2004; Saleh et al., 2013; Garg et al., 2016; Zotter et al., 2017). Higher values of $A A E_{B B}$ result from enhanced light absorption in the near-UV and blue part of the spectrum caused by organic carbon species, present in biomass-smoke. Source specific AAE can be independently determined using auxiliary measurements of OC/EC and ${ }^{14} \mathrm{C}$ (Sandradewi et al., 2008; Zotter et al., 2017), or biomass burning tracers like levoglucosan (Favez et al., 2010; Herich et al., 2014; Hellén et al., 2017; Helin et al., 2018). Since independent measurements allowing the determination of the AAE pair representative for our measurement locations were not available, the most suitable AAE pair was estimated according to the commonly used AAE values published in the literature, by considering overall distribution of $A A E$ (Figure S1) for each measurement location and the corresponding diurnal variation of traffic $\left(B C_{T R}\right)$ and biomass burning related $\mathrm{BC}\left(B C_{\mathrm{BB}}\right)$ (Figure S2). AAE was calculated using the Eq. 1 for $470 \mathrm{~nm}$ and $950 \mathrm{~nm}$ wavelengths, where $b_{a b s}$ stands for the absorption coefficient at $470 \mathrm{~nm}$ and $950 \mathrm{~nm}$.

$A A E=\frac{\ln \left(\frac{b_{a b s(470)}}{b_{a b s(950)}}\right)}{\ln (950 / 470)}$

By taking into account equations provided by Sandradewi et al. (2008), the $B C_{B B}$ and $B C_{T R}$ were finally calculated using the Eq. 2 and 3, respectively.

$$
\begin{aligned}
& B C_{B B}=\frac{\frac{b_{a b s(470)}}{b_{a b s(950)}}-\left(\frac{950}{470}\right)^{A A E_{T R}}}{\left(\frac{950}{470}\right)^{A A E_{B B}}-\left(\frac{950}{470}\right)^{A A E_{T R}}} \times B C \\
& B C_{T R}=B C-B C_{B B}
\end{aligned}
$$

A histogram of absorption Ångström exponent (AAE) derived by Eq. 1 from AE33 measurements for both measurement locations is shown on Fig. S1. For direct comparison, only the time period with available measurements at both locations simultaneously was considered and covers the period from February to May 2017. Winter AAE median values of 1.36 and 1.60 and spring median values of 1.22 and 1.36 are characteristic 
for Ljubljana (L)and Ajdovščina (AJ) location, respectively. Lower AAE values measured in $L$ correspond well to the urban nature of $\mathrm{L}$ measurement site, where stronger influence of traffic on $B C$ concentrations is expected.

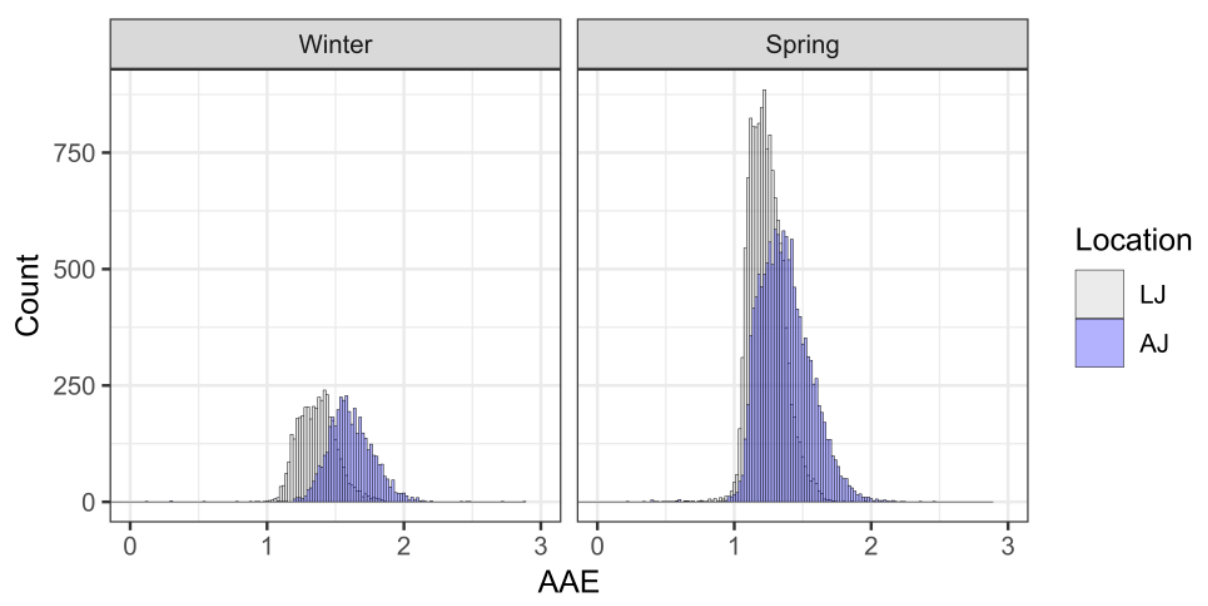

Figure S1: Absorption Ångström exponent (AAE) frequency distributions of 10-minute averages for Ajdovščina (AJ) and Ljubljana (L) for the period from February - May 2017 (winter: February, March; spring: April, May).

The same $A A E_{T R}-A A E_{B B}$ pair of 1.0 and 2.0 was chosen for both measurement locations, based on the evaluation of AAE distribution (Fig. S1). Source apportioned BC concentration (Sandradewi et al., 2008; Zotter et al., 2017) diurnal variation is shown on Fig. S2 for two limiting $A A E_{B B}$ values: 1.7 and 2.0 and fixed $A A E_{T R}=1.0$. The $A A E$ pair of 1.0 and 1.7 results in $B C_{T R}$ and $B C_{B B}$ concentrations presented by blue line, whereas the $A A E$ pair of 1.0 and 2.0 results are presented by red line. Shaded area shows the range of source apportioned concentration between the limiting $A A E_{B B}$ values.

The lower limit of 1.7 for $A A E_{B B}$ is apparently not suitable for $A J$ location, since overall $A A E$ distribution of aerosol mixture in winter often exceeds 2.0 (Fig. S1). The source specific AAE values used for source apportionment are representative for the location and type of combustion, they can be interpreted as "average" values at the specific receptor site. The choice of $A A E_{B B}$ needs to fall just below the maximum values seen at this site (a case of exclusive contribution of biomass burning, allowing still some variation of "real" $A A E_{B B}$, which may vary with time to a certain degree, depending on the primary emissions of combustion and the formation of light absorbing secondary organic aerosol (Kumar et al., 2018)). Moreover, an increase of $B C_{B B}$ causes simultaneous decrease of $B C_{T R}$. This effect can be clearly observed in the Ajdovščina winter diurnal profile after 21:00, when $B C_{T R}$ unrealistically drops to almost zero (Fig. S2C). On the other hand, $A A E_{B B}=2$ results in reasonable diurnal variation of source apportioned $B C$. In winter, $B C_{T R}$ and $B C_{B B}$ concentrations start to increase around 5:00 and exhibit the morning peak between 7:00 and 8:00, when $B C$ is dominated by traffic sources. After daytime dilution in the rising $\mathrm{PBL}$, both $B C_{\mathrm{TR}}$ and $B C_{\mathrm{BB}}$ start to increase between 16:00 and 17:00 due to decreased mixing in the PBL. $B C_{\mathrm{TR}}$ exhibits the afternoon peak around 19:00, whereas $B C_{B B}$ further increases until 21:00. 
AAE distribution at $\mathrm{L}$ location is clearly shifted to lower values, as compared to AJ location, which can be assigned to stronger contribution of traffic sources. However, by considering only the AAE distribution and the diurnal variation of source apportioned $\mathrm{BC}$, without any other independent measurements, it is not possible to define a reliable source specific AAE pair used for source apportionment. Therefore, a suitable AAE pair for source apportionment was evaluated also by re-evaluation of subsequently modelled BC emission rate (discussed in Section 3.4). Average $B C$ biomass burning fraction resulting from source apportionment using two different values of $A A E_{B B}(1.7$ or 2.0$)$ is presented in Table $S 1$.
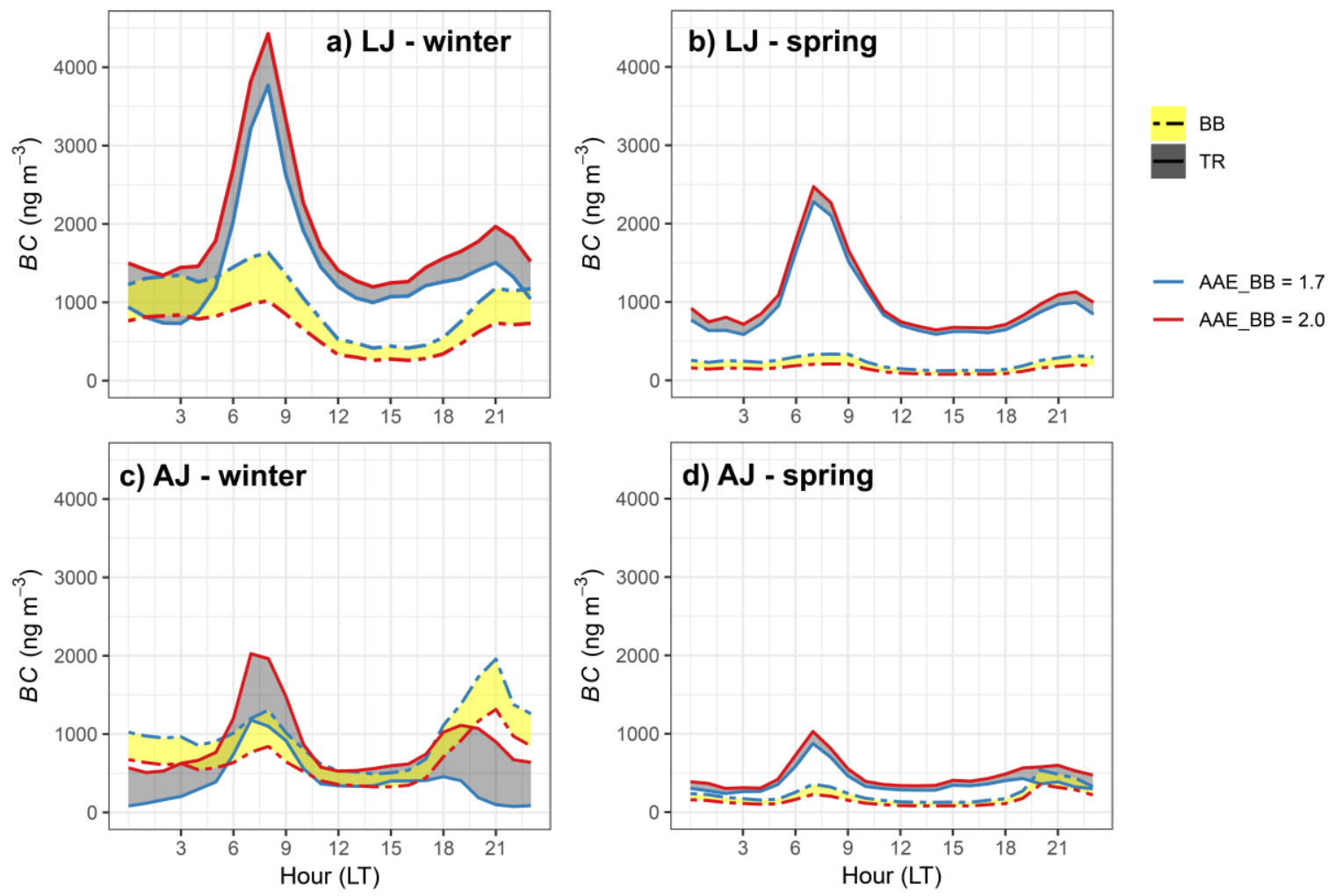

Figure S2: Diurnal variation (local time: CET/CEST) of contribution of traffic $\left(B C_{\mathrm{TR}}\right)$ and biomass burning ( $\left.B C_{\mathrm{BB}}\right)$ to total $B C$ concentration in winter (January - February) and spring (March - April) period for Ljubljana (L) and Ajdovščina (AJ) measurement site, by considering different pairs of absorption Ångström exponents ( $A A E$ ). $A A E_{T R}$ was fixed to 1.0, $A A E_{B B}$ was set to 1.7 (blue line) and 2 (red line). The shaded area represents a range of $B C_{T R}$ (grey) and $B C_{B B}$ (yellow) concentrations calculated between both extreme values of $A A E_{B B}$. Diurnal variation is derived from 1-minute data by considering median of concentration for specific hour. 
Table S1: Average $B C$ biomass burning fraction (BB\%) based on source apportionment using fixed $A A E_{T R}=1.0$ and limit values of 1.7 and 2.0 for $A A E_{B B}$.

\begin{tabular}{|l|l|l|l|l|}
\hline $\begin{array}{l}\text { Measurement } \\
\text { location }\end{array}$ & $\begin{array}{l}\text { Winter } \mathrm{BB} \% \\
\left(A \mathrm{AE}_{\mathrm{BB}}=1.7\right)\end{array}$ & $\begin{array}{l}\text { Winter } \mathrm{BB} \% \\
\left(A \mathrm{AE}_{\mathrm{BB}}=2.0\right)\end{array}$ & $\begin{array}{l}\text { Spring } \mathrm{BB} \% \\
\left(A \mathrm{E}_{\mathrm{BB}}=1.7\right)\end{array}$ & $\begin{array}{l}\text { Spring } \mathrm{BB} \% \\
\left(A A E_{B B}=2.0\right)\end{array}$ \\
\hline $\mathrm{LJ}$ & 51 & 32 & 31 & 20 \\
\hline AJ & 85 & 60 & 53 & 35 \\
\hline
\end{tabular}




\section{S2 BC vertical profile measurements by ultralight aircraft over Ljubljana}

Black carbon vertical profiles (Figure S3) were measured in the Ljubljana basin using an ultralight airplane (Aerospool Dynamic WT9; see GLWF, 2019). The air was sampled using an isokinetic inlet and a modified version of the Aethalometer AE33 with 1 second time resolution (Drinovec et al., 2015). The location of the inlet prevented self-pollution from the airplane exhaust and the inlet was designed to be iso-kinetic at the airplane airspeed. The inlet is a conical diffusor, mounted on the holder of the Pitot tube under the wing, and designed for airspeed $240 \mathrm{~km} / \mathrm{h}$. The plane followed the helical path between $400 \mathrm{~m}$ and $1100 \mathrm{~m}$ a.s.l. (100 - $800 \mathrm{~m}$ a.g.l.). The $\mathrm{BC}$ concentration was used as a parameter quantifying the influence of ground sources on the primary air pollution in the mixing layer and the mixing layer height was estimated from $B C$ vertical profiles $\left(\mathrm{MLH}_{\mathrm{BC}}\right)$. The measured data was fitted using a Boltzmann function:

$$
y=\frac{A_{1}-A_{2}}{1+e^{\left(x-x_{0}\right) / d x}}+A_{2},
$$

where $\mathrm{x}_{0}$ represents the mixing layer height $\left(\mathrm{MLH}_{\mathrm{BC}}\right)$. Comparison of $\mathrm{MLH}_{\mathrm{BC}}$ determined by plane measurements and $\mathrm{Rn}$-model $\left(\mathrm{MLH}_{\mathrm{Rn}}\right)$ are presented in Table S2. The uncertainty of derived $\mathrm{MLH}_{\mathrm{BC}}$ is estimated to be $50 \mathrm{~m}$.

The lower and upper ranges of $\mathrm{MLH}_{\mathrm{Rn}}$ fall within the uncertainty range of $\mathrm{MLH}_{\mathrm{BC}}$.

Table S2: Summary of MLH determined from BC vertical profile measured by plane (MLH $\mathrm{BC}_{\mathrm{BC}}$ ) and MLH determined by $\mathrm{Rn}$ box model $\left(\mathrm{MLH}_{\mathrm{Rn}}\right)$ (data for the closest hour is reported).

\begin{tabular}{|l|c|c|}
\hline Date \& time (UTC) & $\begin{array}{c}\mathrm{MLH}_{\mathrm{BC}} \\
(\mathrm{m} \text { a.g.I. })\end{array}$ & $\begin{array}{c}\mathrm{MLH}_{\mathrm{Rn}}(\mathrm{min}-\mathrm{max}) \\
\text { (m a.g.I.) }\end{array}$ \\
\hline $16 / 02 / 201715: 03$ & 410 & $370(270-460)$ \\
\hline $09 / 03 / 20177: 40$ & 180 & $200(160-240)$ \\
\hline $15 / 03 / 20177: 10$ & 160 & $100(80-110)$ \\
\hline $19 / 05 / 20195: 10$ & 190 & $140(120-160)$ \\
\hline
\end{tabular}



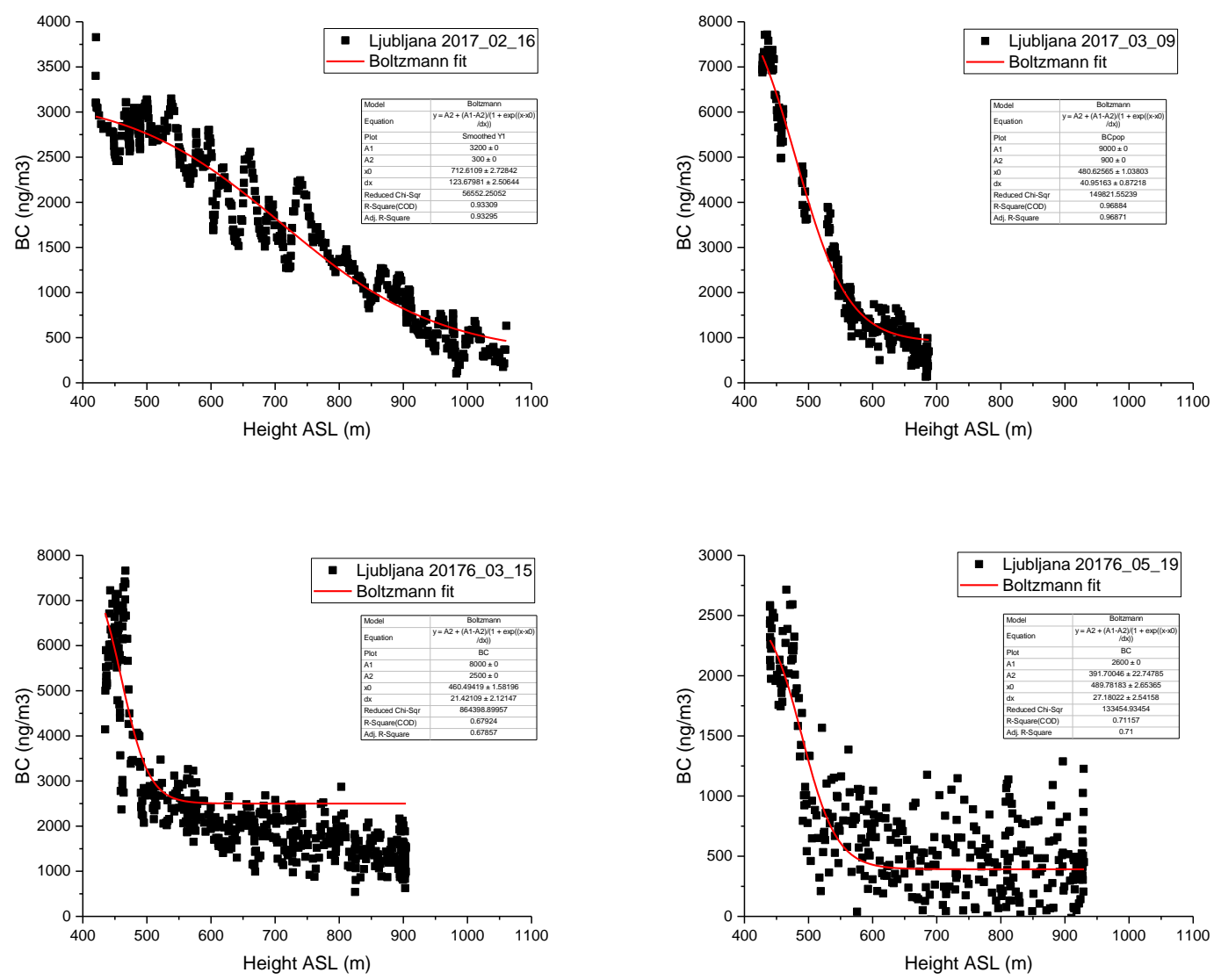

Figure S3: Black carbon vertical profiles above Ljubljana (300 m a.s.I.) at different conditions of atmospheric stability. 


\section{S3 Local wind conditions}
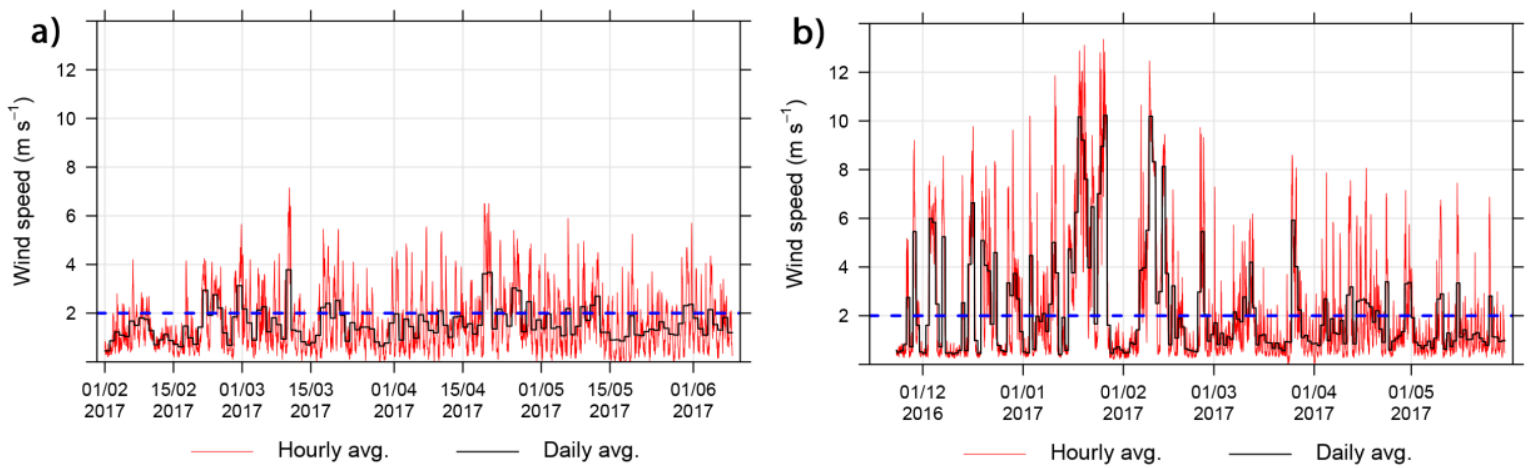

Figure S4: Time series of hourly and daily average wind speeds (ws) for Ljubljana (a) and Ajdovščina (Vipava valley) (b). Dashed blue line represent daily average wind speed of $2 \mathrm{~m} \mathrm{~s}^{-1}$. Days, when daily average ws exceeds the limit value of $2 \mathrm{~m} \mathrm{~s}^{-1}$ are not considered in the analyses.
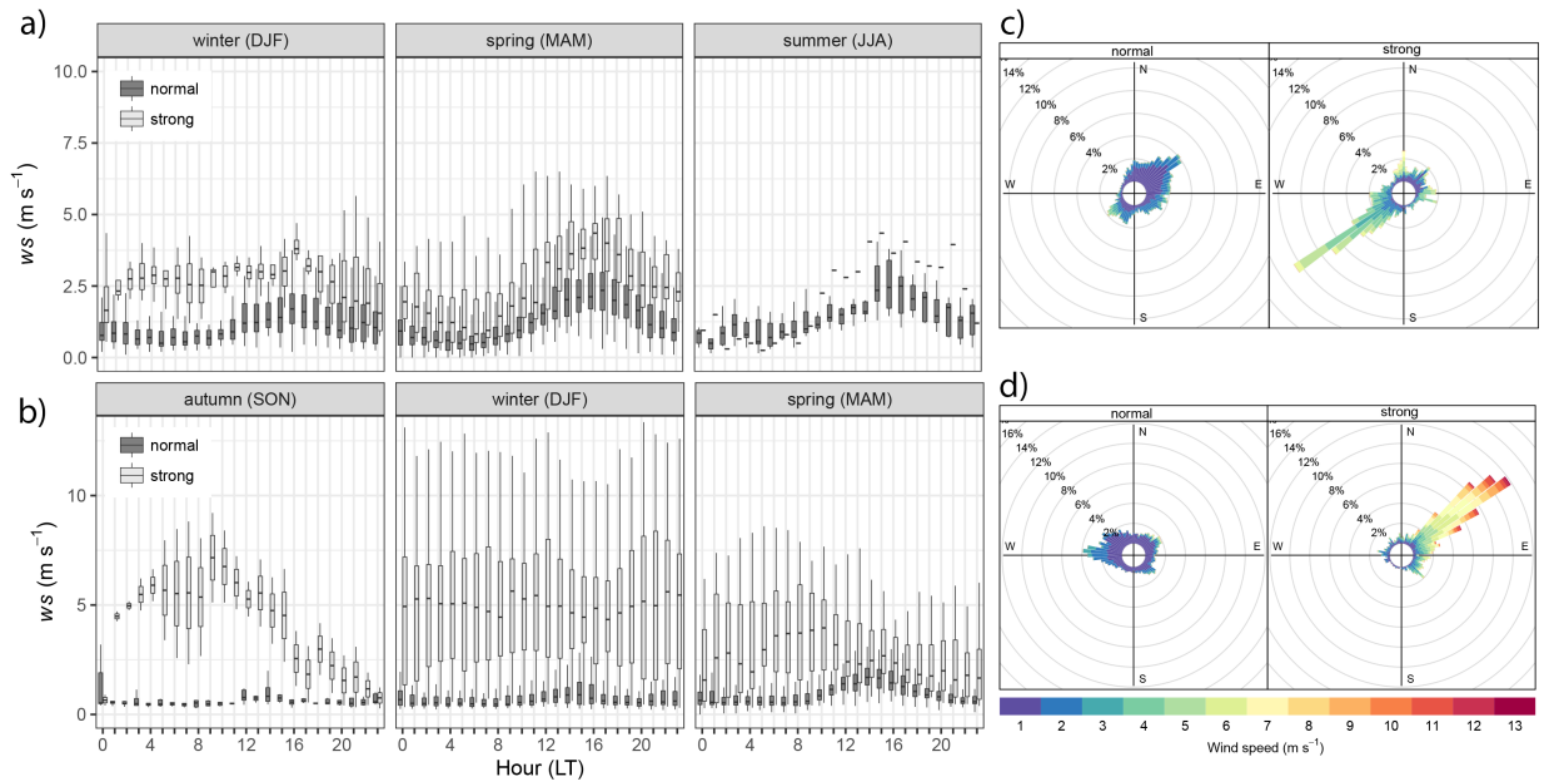

Figure S5: Diurnal variation of wind speed (ws) for normal and strong wind conditions for Ljubljana (a) and Vipava valley (b), grouped by season, and corresponding wind roses for Ljubljana (c) and Vipava valley (d). 


\section{S4 Smoothing of Rn concentration $\left(C_{\mathrm{Rn}}\right)$ measurements}
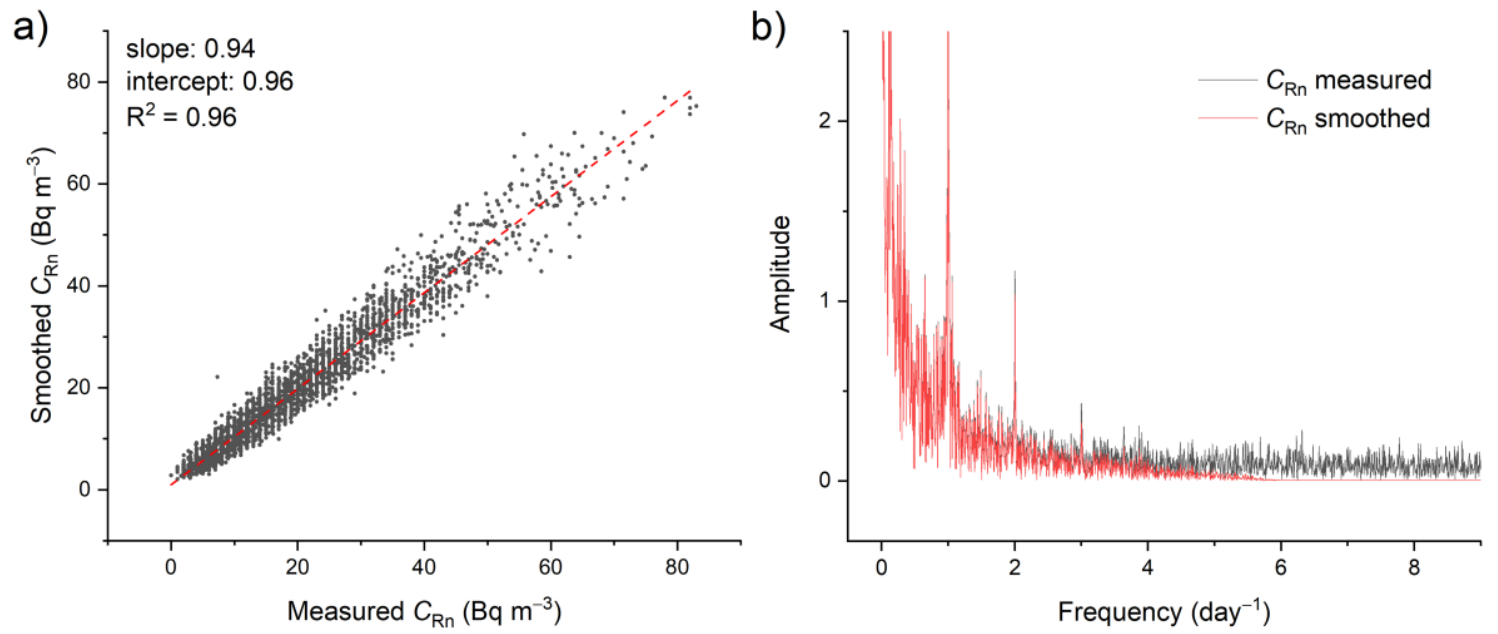

Fig. S6: a) Linear regression between measured $C_{R n}$ and smoothed $C_{R n}$ data for Ljubljana. b) FFT filter with cut-off frequency of $0.25 \mathrm{~h}^{-1}$ was applied to raw data. 


\section{S5}

Estimation of the radon exhalation rate

\section{S5.1 Calibration of $E_{\mathrm{Rn}}$ with the NOAA mixing layer height}

The following procedure was used to compare radon derived MLH and MLH from the NOAA database. This was the first step for the estimation of appropriate monthly resolved $E_{\mathrm{Rn}}$.

1. A subset of the dataset with daily average wind speed below $2 \mathrm{~m} / \mathrm{s}$ limited to the period without rain was used for comparison.

2. In order to avoid the period of day, when both models have the highest uncertainty, only 9 hours from 4:00 $-13: 00$ were considered. Due to 3 hour time resolution of NOAA database, 4 points per day were included in the analyses, namely at 4:00, 7:00, 10:00, 13:00 (CET). A daily average (and standard deviation) of both MLH estimates was used for further analyses (Fig. S7 a).

3. Deming regression (Cornbleet and Gochman, 1979) was applied to obtain the regression slope between MLH from radon data and NOAA MLH data $\left(Z_{i}\right)$ (regression was forced through zero) (Fig. S7 b). Deming regression minimizes the sum of distances in both the $x$ and $y$ direction. Standard deviation in $x$ and $y$ were used with the confidence level of $95 \%$. Consequently, days with more stable atmospheric conditions have higher influence on the slope of regression.

4. The $E_{\mathrm{Rn}}$ which resulted in the slope of unity was considered as the most appropriate $E_{\mathrm{Rn}}$ estimate. $E_{\mathrm{Rn}}$ was rounded to $50 \mathrm{~Bq} \mathrm{~m}{ }^{-2} \mathrm{~h}^{-1}$ with $100 \mathrm{~Bq} \mathrm{~m}^{-2} \mathrm{~h}^{-1}$ acceptable range.

a)

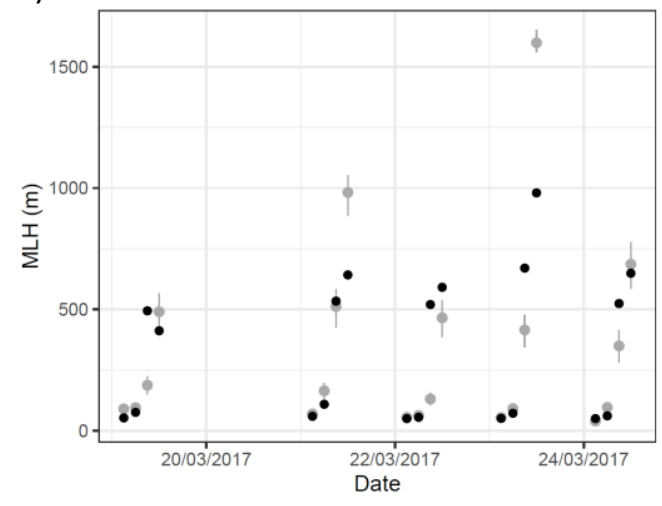

b)

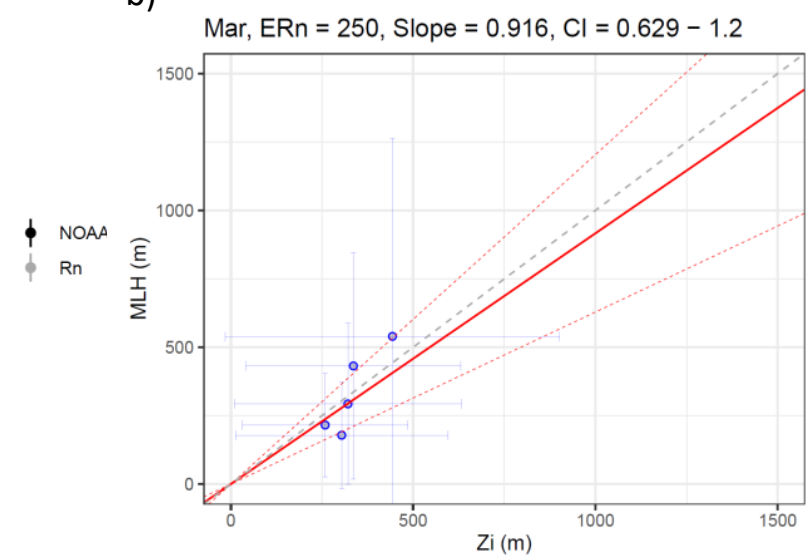

Fig. S7 Example of a subset of data for Ljubljana from $19-24$ March, 2017. Data points for 4:00, 7:00, 10:00 and 13:00 (CET) (matching the 3 hour time resolution of NOAA dataset) were considered. MLH obtained from the radon model is presented by a point and range calculated for $100 \mathrm{~Bq} \mathrm{~m}^{2} \mathrm{~h}^{-1}$ range $\left(200,250\right.$ and $300 \mathrm{~Bq} \mathrm{~m}^{2} \mathrm{~h}^{-1}$ are used in the selected case). Data for March 20 are omitted from the comparison due to average daily wind speed exceeding the value of

$2 \mathrm{~m} \mathrm{~s}^{-1}$. b) Deming regression is fitted through daily averages (and standard deviation) of MLH. Red dotted line represents the lower and upper $95 \%$ confidence interval, dashed grey line represents 1:1 line. 


\section{S5.2 Monthly estimates of radon exhalation rate}

Appropriate $E_{\mathrm{Rn}}$ was determined based on combination of three different approaches, as explained in Section 2.5 of the main text. Selected cases are presented for each month for $L J$ and AJ location.

1. The slope of unity between radon based MLH and NOAA MLH data obtained by the procedure explained in the section Supplement 5.1, represents the first best estimate of $E_{R n}$ (Fig. S8). In the case of high uncertainty (low number of data points, wide confidence interval range, unrealistic values of $E_{\mathrm{Rn}}$ estimate), the second approach was used to confirm the previously obtained $E_{\mathrm{Rn}}$ estimates or to obtain a suitable range of $E_{\mathrm{Rn}}$.

2. In the second phase estimated $E_{\mathrm{Rn}}$ was evaluated by comparison of black carbon concentration measured at different elevation (city-hill). Strong vertical gradient in concentration indicates period when MLH is below the upper measurement site (hill).

3. Lastly, radon based MLH was compared to the MLH estimated from the vertical BC profile measured by light aircraft in $\mathrm{L}$ and with lidar measurement for AJ location. When the data were available, the third approach was used superior to the approach 1 and 2 .

a)

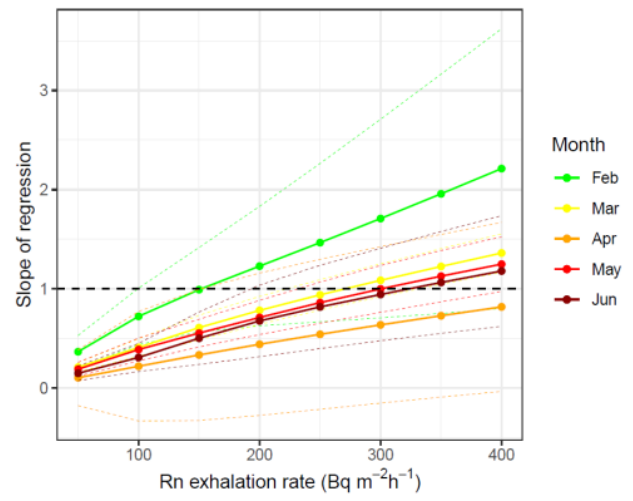

b)

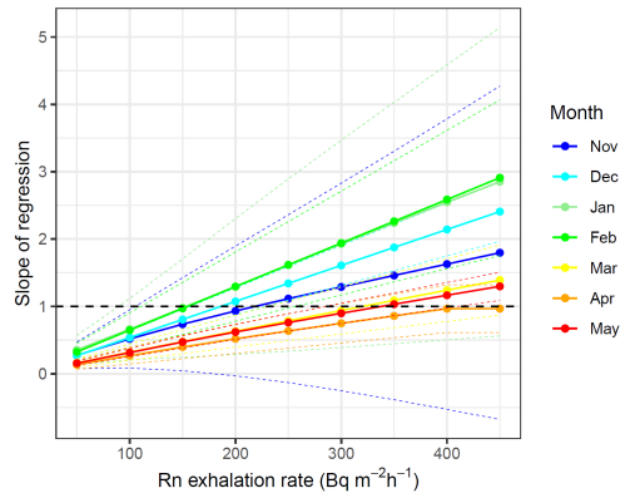

Fig 58: Dependence of the slope of the Deming regression between calculated MLH from Rn measurements and NOAA data, on Rn exhalation rate for Ljubljana (a) and Vipava valley (b). This is used to determine the Rn exhalation rate at unity slope in the first phase. Points are connected with line for visualization purposes only. Dotted lines represent the envelope of $95 \%$ confidence interval. 
Ljubljana

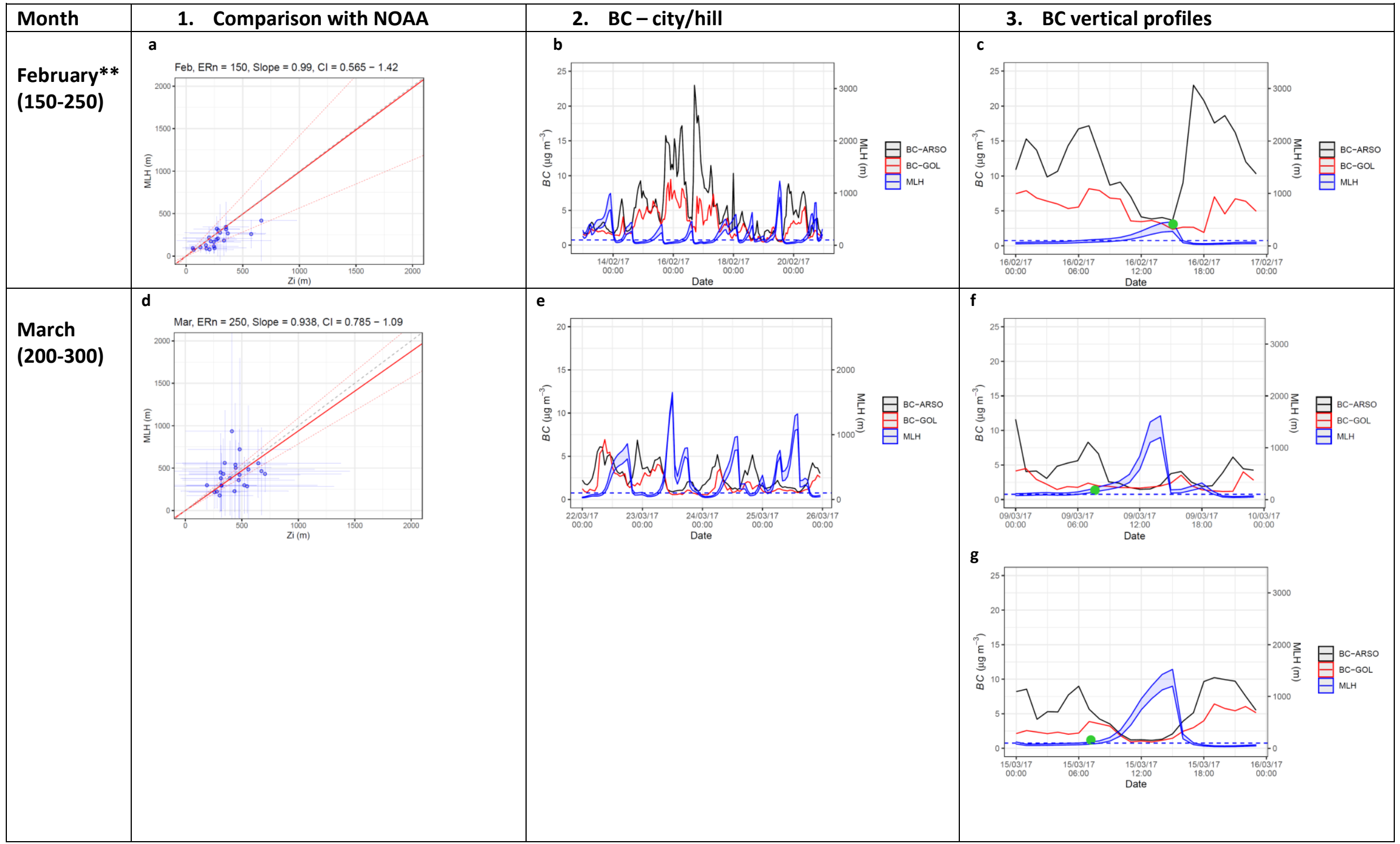




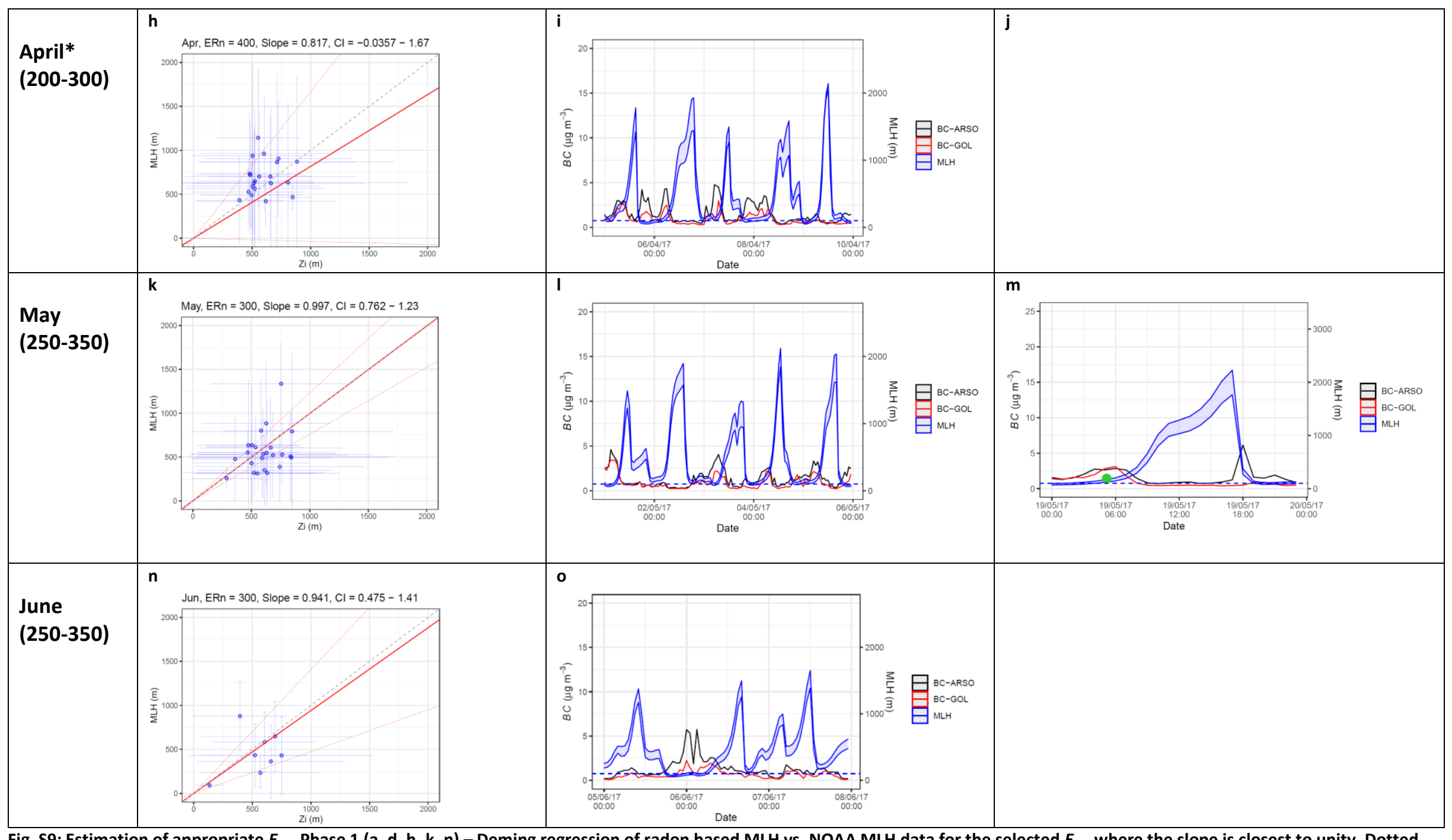

Fig. S9: Estimation of appropriate $E_{\mathrm{Rn}}$. Phase $1(\mathrm{a}, \mathrm{d}, \mathrm{h}, \mathrm{k}, \mathrm{n})$ - Deming regression of radon based MLH vs. NOAA MLH data for the selected $E_{\mathrm{Rn}}$ where the slope is closest to unity. Dotted red line represents lower and upper confidence interval. Phase $2(b, e, i, l, o)$ : Comparison of the range of radon based MLH (blue lines) and black carbon concentration measured at two elevations (BC-ARSO: city, BC-GOL: (hill)), dashed blue line represents the elevation of the hill site. Phase $3(c, f, g, m)$ : same as phase 2 plots, green dot represents $M L H$ determined from $\mathrm{BC}$ vertical profiles based on aircraft measurements. * $E_{\mathrm{Rn}}$ was estimated based on phase $2,{ }^{* *}$ - $E_{\mathrm{Rn}}$ was estimated based on phase 3. 


\section{Vipava valley}

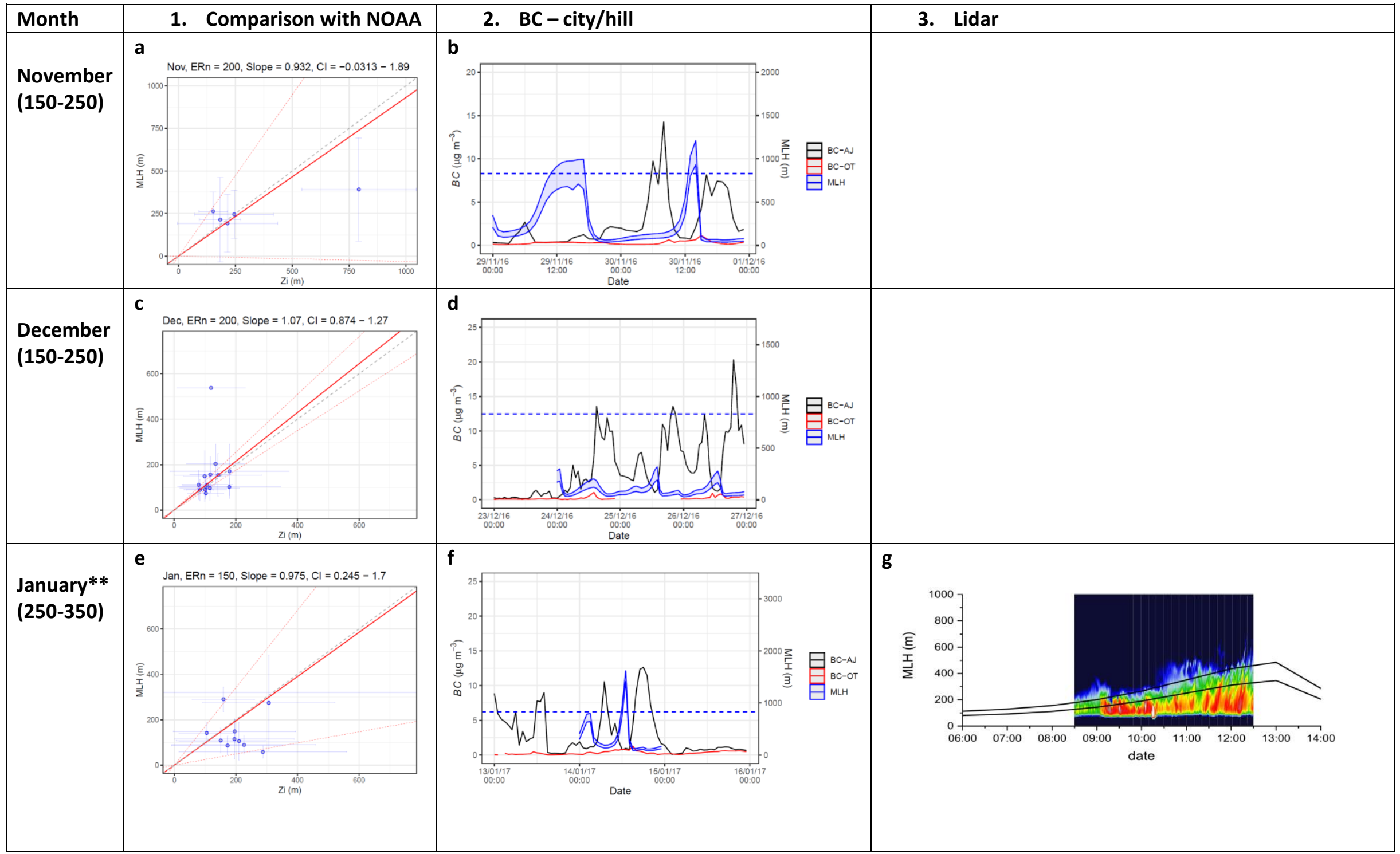




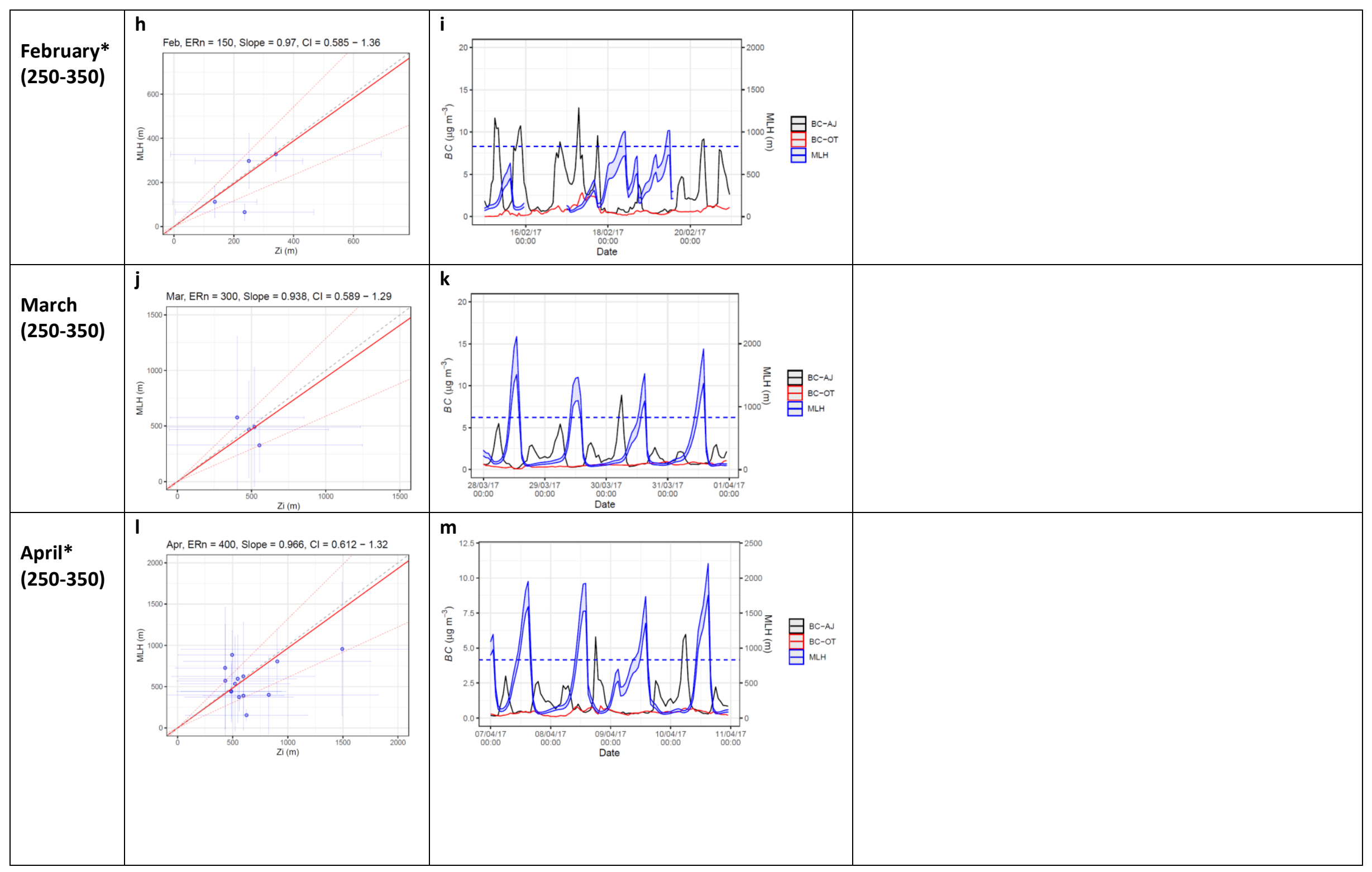




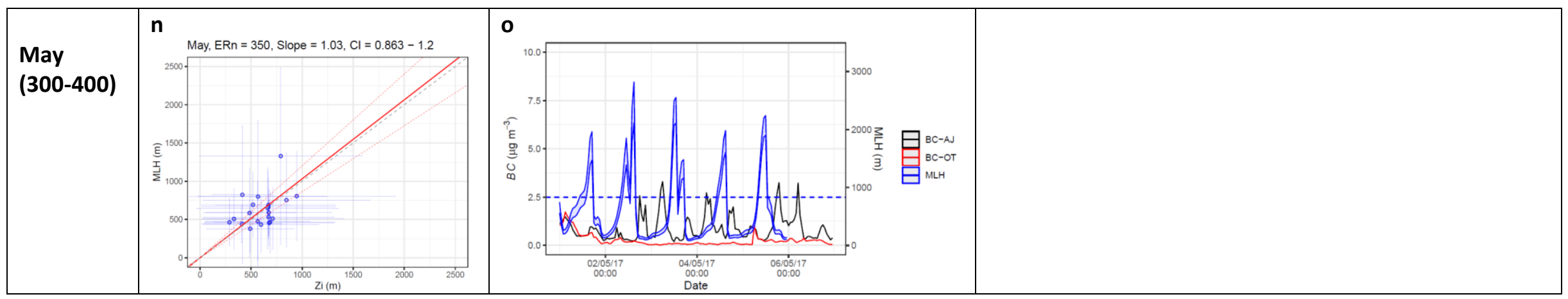

Fig. S10: Estimation of appropriate $E_{\mathrm{Rn}}$. Phase $1(\mathrm{a}, \mathrm{c}, \mathrm{e}, \mathrm{h}, \mathrm{j}, \mathrm{l}, \mathrm{n})$ - Deming regression of radon based MLH vs. NOAA MLH data for the selected $E_{\mathrm{Rn}}$ where the slope is closest to unity. Dotted red line represents lower and upper confidence interval. Phase 2 (b, $d, f, l, k, m, 0)$ : Comparison of the range of rad on based MLH (blue lines) and black carbon concentration measured at two elevations (BC-ARSO: city, BC-GOL: (hill)), dashed blue line represents the elevation of the hill site. Phase 3 (g): Comparison of the range of modelled MLH (black lines) over the Vipava valley with range-corrected lidar return signal on $09 / 01 / 2017 .{ }^{*}-E_{\mathrm{Rn}}$ was estimated based on phase $2,{ }^{* *}-E_{\mathrm{Rn}}$ was estimated based on phase 3. 


\section{S6 Sensitivity analyses of spatial decay constant}

Sensitivity analyses of modelled $E_{\mathrm{TR}}$ for different $\gamma_{T R}$ values were performed based on comparison with measured traffic density at representative street section, which connects two of Ljubljana arteries leading from the ring to the city center (Figure S11). Traffic during working days in Ljubljana is characterized by two significant peaks, morning peak between 7:00 and 9:00 and afternoon peak between 15:00 and 17:00. The fraction of freight vehicles is higher in morning hours, whereas mainly car traffic is characteristic for afternoon hours. After 17:00 traffic density decreases towards midnight and is the lowest between midnight and 4:00. Sunday diurnal pattern significantly differs from working days by about $50 \%$ smaller traffic density and the missing morning peak.

Linear regression (presented as $\mathrm{R}^{2}$ ) between normalized traffic density (normalized by mean) diurnal profile and normalized $E_{\mathrm{TR}}$ diurnal profile (normalized by median values) for different choice of spatial decay constant $\left(\gamma_{\mathrm{TR}}\right)$ is presented on Figure 12 and S12 b. Linear regression was forced through zero for the time period 00:00 - 10:00, when the uncertainty of the model is expected to be the lowest. The strength of correlation is the highest for $\gamma_{\mathrm{TR}}$

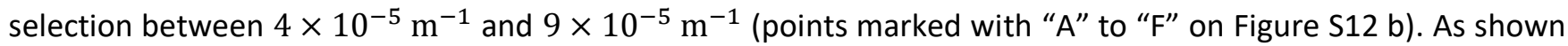
by diurnal evolution (in terms of median $E_{\mathrm{TR}}$ ) on Figure $S 12 \mathrm{c}$, the reason for weaker correlation with traffic density for point " $G$ " is the overestimation of $E_{\mathrm{TR}}$ in the afternoon hours, which is caused by stronger wind speeds in afternoon hours and higher uncertainty of the MLH estimates. Decreasing $\gamma_{\mathrm{TR}}$ from " $\mathrm{D}$ " to " $\mathrm{B}$ " would cause $26 \%$ lower median $E_{\mathrm{TR}}$ calculated for the afternoon peak emissions at 15:00, when the highest model uncertainty is expected. On the other hand, increasing $\gamma_{\mathrm{TR}}$ from " $\mathrm{D}$ " to " $\mathrm{G}$ " would result in $33 \%$ higher $E_{\mathrm{TR}}$ for the same time period.
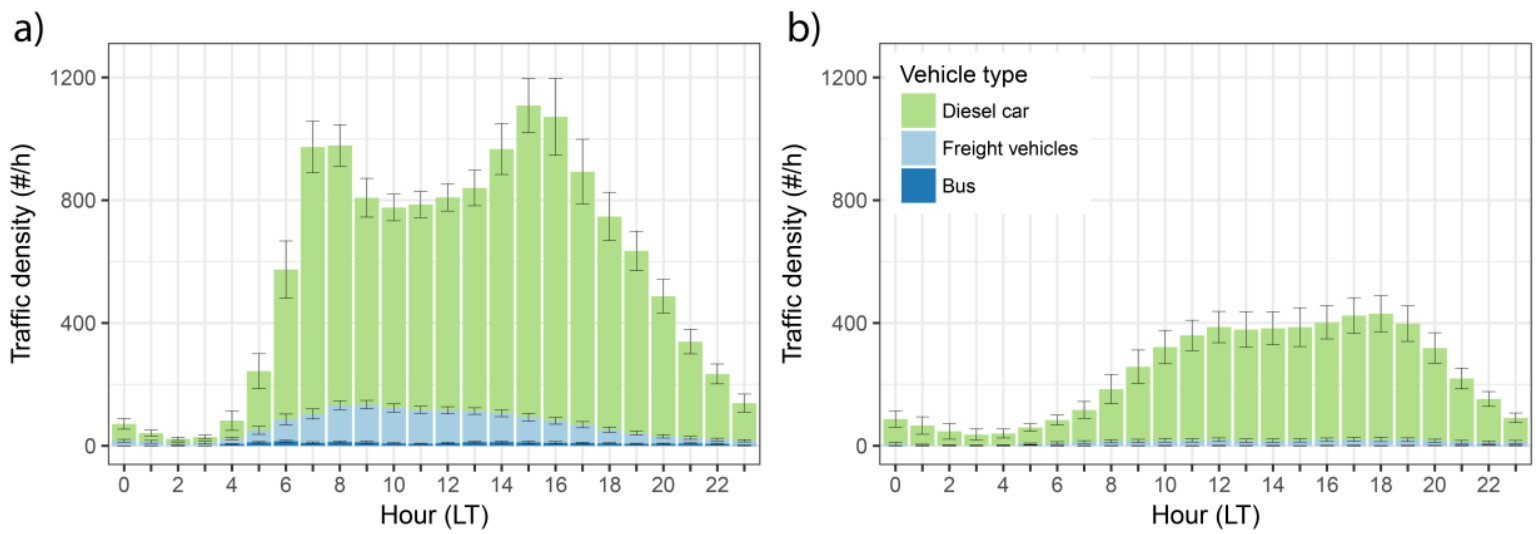

Figure S11: Mean traffic density (and standard deviation) for working days (a) and Sundays (b) for diesel cars, freight vehicles and buses. The ratio between gasoline and diesel cars in Slovenia is 55 (gasoline):45(diesel) (Si-Stat, 2019)(Si-Stat, 2019). 
a)

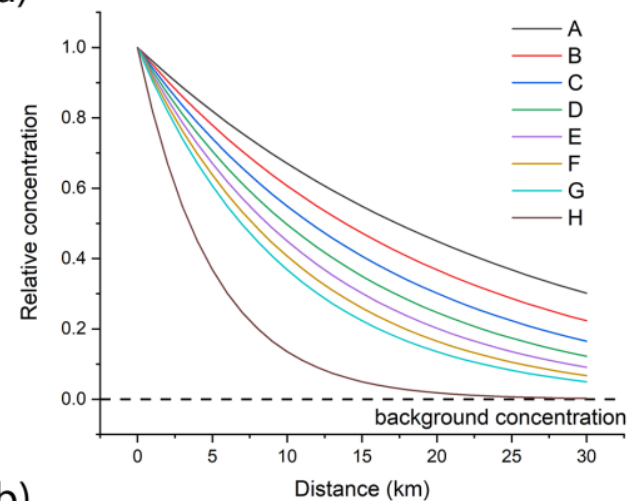

\begin{tabular}{|l|l|}
\hline Label & $\boldsymbol{\gamma}\left(\mathbf{m}^{-\mathbf{1}}\right)$ \\
\hline A & $4 \times 10^{-5}$ \\
\hline B & $5 \times 10^{-5}$ \\
\hline C & $6 \times 10^{-5}$ \\
\hline D & $7 \times 10^{-5}$ \\
\hline E & $8 \times 10^{-5}$ \\
\hline F & $9 \times 10^{-5}$ \\
\hline G & $1 \times 10^{-4}$ \\
\hline H & $2 \times 10^{-4}$ \\
\hline
\end{tabular}

b)

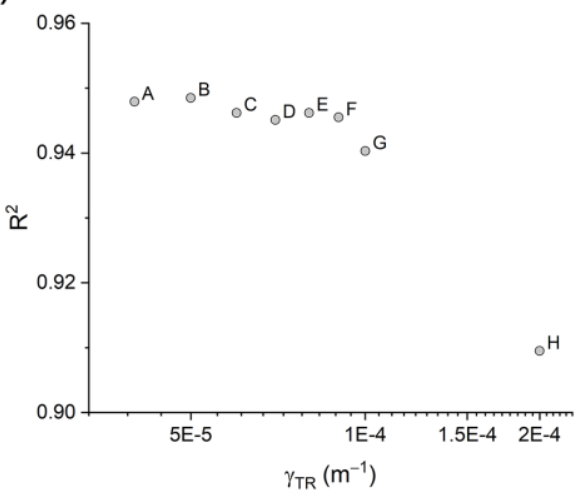

C)

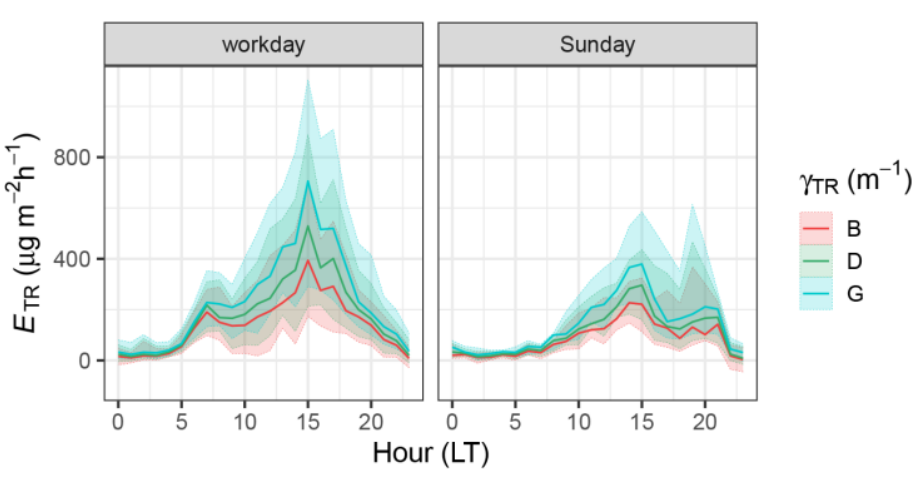

Figure S12: Dependence of modelled $E_{\mathrm{TR}}$ on the choice of horizontal advection term. a) Spatial decrease of $\mathrm{BC}$ concentration from the source by different $\gamma$. Labels are explained in the table. b) Dependence of $R^{2}$ for correlation between normalized diurnal profile of traffic density and normalized diurnal profile (in terms of median hourly values) of modelled $E_{\mathrm{TR}}$ for Ljubljana from midnight to 10:00. c) Diurnal profile of modelled $E_{\mathrm{TR}}$ for selected cases of $\gamma_{\mathrm{TR}}$ for Ljubljana: line - median, shaded area $-25^{\text {th }}$ to $75^{\text {th }}$ quantile. 


\section{References}

Cornbleet, P. J., and Gochman, N.: Incorrect least-squares regression coefficients in method-comparison analysis, Clinical chemistry, 25, 432-438, 1979.

Drinovec, L., Močnik, G., Zotter, P., Prévôt, A. S. H., Ruckstuhl, C., Coz, E., Rupakheti, M., Sciare, J., Müller, T., Wiedensohler, A., and Hansen, A. D. A.: The "dual-spot" Aethalometer: an improved measurement of aerosol black carbon with real-time loading compensation, Atmos. Meas. Tech., 8, 1965-1979, 10.5194/amt-8-1965-2015, 2015.

Favez, O., El Haddad, I., Piot, C., Boréave, A., Abidi, E., Marchand, N., Jaffrezo, J. L., Besombes, J. L., Personnaz, M. B., Sciare, J., Wortham, H., George, C., and D'Anna, B.: Inter-comparison of source apportionment models for the estimation of wood burning aerosols during wintertime in an Alpine city (Grenoble, France), Atmos. Chem. Phys., 10, 5295-5314, 10.5194/acp-10-5295-2010, 2010.

Garg, S., Chandra, B. P., Sinha, V., Sarda-Esteve, R., Gros, V., and Sinha, B.: Limitation of the Use of the Absorption Angstrom Exponent for Source Apportionment of Equivalent Black Carbon: a Case Study from the North West Indo-Gangetic Plain, Environmental science \& technology, 50, 814-824, 10.1021/acs.est.5b03868, 2016.

GLWF: https://www.worldgreenflight.com/, access: May 27, 2019.

Helin, A., Niemi, J. V., Virkkula, A., Pirjola, L., Teinilä, K., Backman, J., Aurela, M., Saarikoski, S., Rönkkö, T., Asmi, E., and Timonen, H.: Characteristics and source apportionment of black carbon in the Helsinki metropolitan area, Finland, Atmos. Environ., 190, 87-98, 10.1016/j.atmosenv.2018.07.022, 2018.

Hellén, H., Kangas, L., Kousa, A., Vestenius, M., Teinilä, K., Karppinen, A., Kukkonen, J., and Niemi, J. V.: Evaluation of the impact of wood combustion on benzo[a]pyrene (BaP) concentrations; ambient measurements and dispersion modeling in Helsinki, Finland, Atmos. Chem. Phys., 17, 3475-3487, 10.5194/acp-17-3475-2017, 2017.

Herich, H., Gianini, M. F. D., Piot, C., Močnik, G., Jaffrezo, J. L., Besombes, J. L., Prévôt, A. S. H., and Hueglin, C.: Overview of the impact of wood burning emissions on carbonaceous aerosols and PM in large parts of the Alpine region, Atmos. Environ., 89, 64-75, http://dx.doi.org/10.1016/j.atmosenv.2014.02.008, 2014.

Kirchstetter, T. W.: Evidence that the spectral dependence of light absorption by aerosols is affected by organic carbon, Journal of Geophysical Research, 109, 10.1029/2004jd004999, 2004.

Kumar, N. K., Corbin, J. C., Bruns, E. A., Massabó, D., Slowik, J. G., Drinovec, L., Močnik, G., Prati, P., Vlachou, A., Baltensperger, U., Gysel, M., El-Haddad, I., and Prévôt, A. S. H.: Production of particulate brown carbon during atmospheric aging of wood-burning emissions, Atmos. Chem. Phys., 18, 17843-17861, 10.5194/acp-18-178432018, 2018.

Saleh, R., Hennigan, C. J., McMeeking, G. R., Chuang, W. K., Robinson, E. S., Coe, H., Donahue, N. M., and Robinson, A. L.: Absorptivity of brown carbon in fresh and photo-chemically aged biomass-burning emissions, Atmos. Chem. Phys., 13, 7683-7693, 10.5194/acp-13-7683-2013, 2013. 
Sandradewi, J., Prévôt, A. S. H., Szidat, S., Perron, N., Alfarra, M. R., Lanz, V. A., Weingartner, E., and Baltensperger, U.: Using aerosol light absorption measurements for the quantitative determination of wood burning and traffic emission contributions to particulate matter, Environ. Sci. Technol., 42, 3316-3323, 10.1021/es702253m, 2008.

Statistical Office of Republic of Slovenia (Si-Stat): https://pxweb.stat.si/SiStat, access: June 24, 2019, 2019.

Zotter, P., Herich, H., Gysel, M., El-Haddad, I., Zhang, Y., Močnik, G., Hüglin, C., Baltensperger, U., Szidat, S., and Prévôt, A. S. H.: Evaluation of the absorption Ångström exponents for traffic and wood burning in the Aethalometer-based source apportionment using radiocarbon measurements of ambient aerosol, Atmos. Chem. Phys., 17, 4229-4249, 10.5194/acp-17-4229-2017, 2017. 